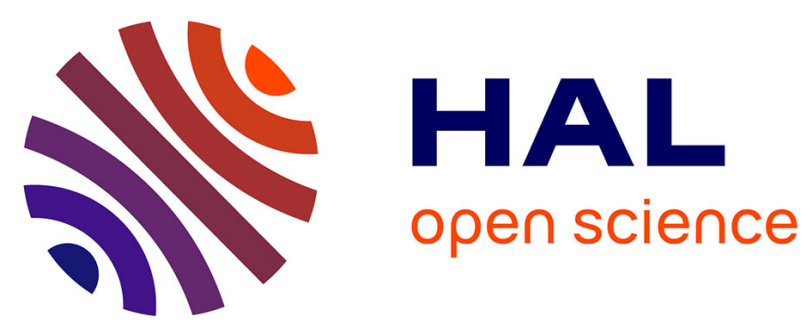

\title{
Broadband Mid Infrared Photonic Integrated components using a Ge-rich SiGe platform
}

\author{
Vladyslav Vakarin, Joan Manel Ramírez, Qiankun Liu, Xavier Le Roux, \\ Jacopo Frigerio, Andrea Ballabio, Laurent Vivien, Giovanni Isella, Delphine \\ Marris-Morini
}

\section{To cite this version:}

Vladyslav Vakarin, Joan Manel Ramírez, Qiankun Liu, Xavier Le Roux, Jacopo Frigerio, et al.. Broadband Mid Infrared Photonic Integrated components using a Ge-rich SiGe platform. IEEE Group IV Photonics, Aug 2017, Berlin, Germany. hal-01617229

\section{HAL Id: hal-01617229 https://hal.science/hal-01617229}

Submitted on 16 Oct 2017

HAL is a multi-disciplinary open access archive for the deposit and dissemination of scientific research documents, whether they are published or not. The documents may come from teaching and research institutions in France or abroad, or from public or private research centers.
L'archive ouverte pluridisciplinaire HAL, est destinée au dépôt et à la diffusion de documents scientifiques de niveau recherche, publiés ou non, émanant des établissements d'enseignement et de recherche français ou étrangers, des laboratoires publics ou privés. 


\title{
Broadband Mid Infrared Photonic Integrated components using a Ge-rich SiGe platform
}

\author{
Vladyslav Vakarin ${ }^{1}$, Joan Manel Ramirez ${ }^{1, *}$, Qiankun Liu ${ }^{1}$, Xavier Le Roux ${ }^{1}$, Jacopo Frigerio ${ }^{2}$, \\ Andrea Ballabio ${ }^{2}$, Laurent Vivien ${ }^{1}$, Giovanni Isella ${ }^{2}$, and \\ Delphine Marris-Morini ${ }^{1}$ \\ ${ }^{1}$ Centre de Nanosciences et de Nanotechnologies, CNRS, Univ. Paris-Sud, Université Paris-Saclay, C2N-Orsay, 91405 Orsay cedex, \\ France \\ ${ }^{2}$ L-NESS, Dipartimento di Fisica, Politecnico di Milano, Polo di Como, Via Anzani 42, 22100 Como, Italy \\ *e-mail : joan-manel.ramirez@u-psud.fr
}

\begin{abstract}
We demonstrate low-loss mid infrared photonic integrated components fabricated on a Ge-rich $\mathrm{Si}_{1-\mathrm{x}} \mathbf{G e}_{\mathrm{x}}$ platform. These devices show broadband operation over a wavelength range of at least from $\lambda \approx 5.1 \mu \mathrm{m}$ to $\lambda \approx 8.6$ $\mu \mathrm{m}$, and comprise waveguides, multimode interference couplers and Mach-Zehnder interferometers.
\end{abstract}

Keywords: Mid infrared; Silicon; Germanium; Integrated photonics; Waveguides; Mach-Zehnder Interferometer.

\section{INTRODUCTION}

Mid-IR systems are recently gaining attention due to the foreseen outstanding functionality of a large pool of devices upon integration in an efficient, compact and cost-effective platform [1]. Such new approach is expected to provide solutions in many fields including sensing, imaging, healthcare or secure communication networks, among others [2].

To accomplish such a challenging task, mid-IR devices should be processed in a suitable technology yielding robust performance while being able to cope with the processing constraints of the new designs. In that regard, the use of Si-based platforms is particularly interesting, as it provides access to the mainstream CMOS technology. Indeed, the combination of $\mathrm{Si}$ and $\mathrm{Ge}$ as raw materials either in the form of Ge-on-Si or by using $\mathrm{Si}_{1-\mathrm{x}} \mathrm{Ge}_{\mathrm{x}}$ alloys appears very promising to develop mid-IR photonic integrated circuits (PICs) due to the large transparency window of both materials $(\lambda \approx$ $8 \mu \mathrm{m}$ for $\mathrm{Si}$ and $\lambda \approx 15 \mu \mathrm{m}$ for $\mathrm{Ge}$ ) and the suppression of Two-Photon Absorption (TPA) at the early mid-IR region $(\lambda \approx 2.2 \mu \mathrm{m}$ for $\mathrm{Si}$ and $\lambda \approx 3.2 \mu \mathrm{m}$ for $\mathrm{Ge})[3,4]$. Moreover, such latter advantage can be leveraged to design active devices by taking advantage of the $\mathrm{Si}$ and Ge third-order optical susceptibility with no TPA penalty under high pumping regime $[5,6]$. Within this framework we recently demonstrated the potential of Ge-rich $\mathrm{Si}_{0.2} \mathrm{Ge}_{0.8}$ waveguides on graded substrates for the development of new mid-IR circuits, and we reported low propagation loss of $1.5+/-0.5 \mathrm{~dB} / \mathrm{cm}$ at $4.6 \mu \mathrm{m}$ wavelength [7].

We now report on the development of a series of mid-IR components and interferometric devices, using this Ge-rich $\mathrm{Si}_{1-\mathrm{x}} \mathrm{Ge}_{\mathrm{x}}$ platform. As a main advantage we demonstrate flat response in a wide spectral range, from 5.1 to $8.6 \mu \mathrm{m}$ wavelength, only limited by the experimental set-up. This work opens new perspectives for operation in an ultra-wide spectral range in the midIR.

\section{DEVICE DESIGN AND FABRICATION}

The devices are based on the Ge-rich $\mathrm{Si}_{1-\mathrm{x}} \mathrm{Ge}_{\mathrm{x}}$ epilayer reported in figure 1. A $11 \mu \mathrm{m}$-thick graded buffer layer with a linear increase of the $\mathrm{Ge}$ concentration from $\mathrm{x}=0$ up to $\mathrm{x}=0.79$ was deposited over a Si substrate by Low Energy Plasma Enhanced Chemical Vapour Deposition (LEPECVD). Then, a 2 $\mu \mathrm{m}$-thick $\mathrm{Si}_{0.2} \mathrm{Ge}_{0.8}$ layer was grown on top, to be used as the guiding core. Such configuration provides a gradual accommodation of the lattice parameter along the vertical direction, resulting in a low threading dislocation density (TDD) of around $3 \times 10^{6} \mathrm{~cm}^{-2}$ and therefore a high quality platform to develop photonic devices [7].

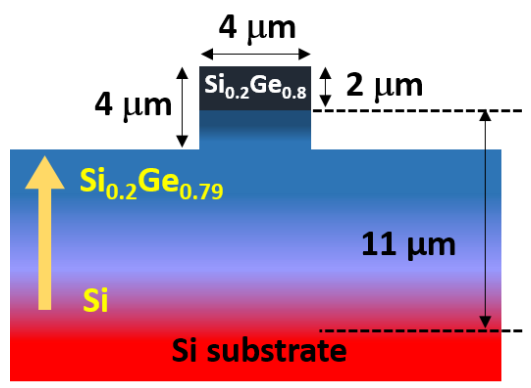

Fig.1 (a) Representative waveguide cross-section scheme using the Ge-rich $\mathrm{Si}_{1-\mathrm{X}} \mathrm{Ge}_{\mathrm{x}}$ platform.

The mid-IR devices are based on the waveguide cross-section displayed in figure 1 . The waveguide width is $4 \mu \mathrm{m}$ and the etching depth is $4 \mu \mathrm{m}$. The waveguides are enlarged at the input/output of the photonic integrated circuit, up to a width of $50 \mu \mathrm{m}$ in order to provide good fiber-waveguide mode matching. Additionally, adiabatic tapers were designed, followed by a single mode waveguide region to filter out higher order propagation modes. Within this platform a large variety of devices can be implemented, such as resonators, spirals waveguides, or interferometric structures.

\section{Characterization}


We report here the characterization of asymmetric Mach Zehdner Interferometer (MZIs). The Mach Zehnders arms are $3.2 \mathrm{~mm}$-long, with a length difference of $48 \mu \mathrm{m}$ between both arms. Multimode Intereferometers have been designed as couplers/combiners for the studied wavelength range.

Devices were characterized using the experimental setup described in figure 2. The mid-IR source is a tunable MIRCAT laser, using external Cavity Quantum Cascade Lasers working in pulsed operation (repetition rate of $100 \mathrm{kHz}$ and a duty cycle of $5 \%$ ), which provide a maximum peak intensity of $300 \mathrm{~mW}$ around of $6.5 \mu \mathrm{m}$ and cover the wavelength range from $5.1 \mu \mathrm{m}$ to $8.6 \mu \mathrm{m}$. The output beam is then coupled to a single mode micro-structured fiber for waveguide butt-coupling. A free-space collection system composed by an aspheric lens and a series of mirrors was used to collect and drive the output signal towards the polarizer first and then towards the MCT detector of a mid-IR spectrometer. A lock-in amplifier synchronizes the collected signal with the laser pulses. Samples were characterized in quasi-TM polarization.

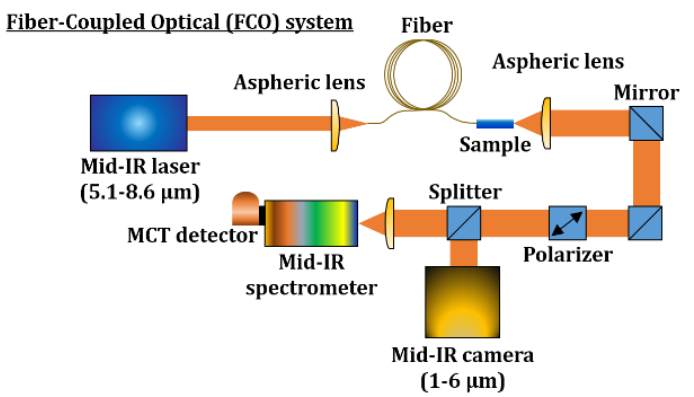

Fig.2. Experimental setup used to characterize the mid infrared devices and components.

Broadband transmission measurements were carried out by sweeping the laser signal all over the available wavelength range, from $\lambda=5.1 \mu \mathrm{m}$ to $\lambda=8.6 \mu \mathrm{m}$ in steps of $1 \mathrm{~nm}$.

As observed in figure 3 (black line), straight waveguides provide flat optical transmission in the entire wavelength range, with coupling losses of around $4 \mathrm{~dB} /$ facet and propagation losses $<5 \mathrm{~dB} / \mathrm{cm}$ regardless of the wavelength. MZIs were characterized with the same procedure. The measured Free Spectral Range (FSR) is related to the length difference between both arms. At least $10 \mathrm{~dB}$ of extinction ratio is obtained in the entire wavelength range, demonstrating a broadband robust operation.

Further analysis of these new mid-IR devices will be presented, providing a reasoned explanation of the origin of such broadband operation. Moreover, a route map for future device development (resonators, grating couplers or Fabry-Perot cavities) and more complex mid-IR integrated systems (integrated spectrometers, label-free sensing schemes) using the Ge-rich $\mathrm{Si}_{1-\mathrm{x}} \mathrm{Ge}_{\mathrm{x}}$ platform will be detailed.

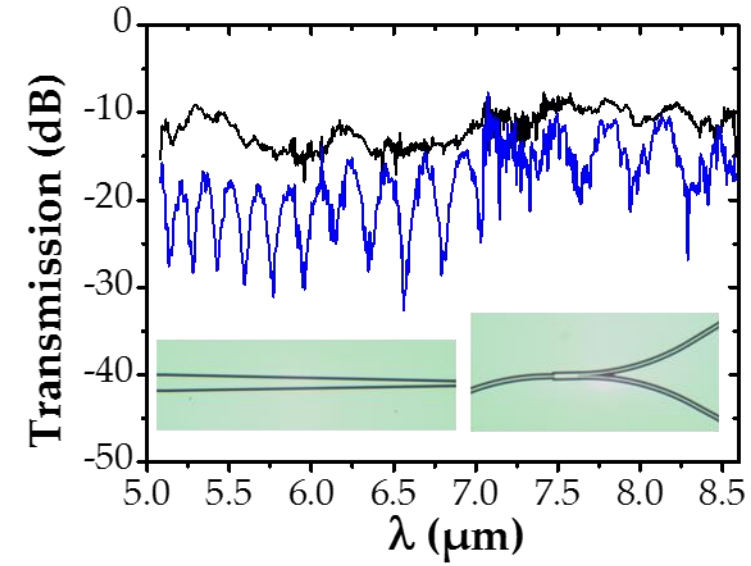

Fig.3. Total waveguide (black line) and MZI (blue line) optical transmission (quasi-TM polarization), comprising coupling and propagation losses. Noticeably, the strong fiber absorption lines around $\lambda \approx 7 \mu \mathrm{m}$ provide a noisy response in this range. Bottom insets show the fabricated adiabatic taper (left) and the MMI (right).

\section{CONCLUSION}

Several mid-IR photonic integrated components have been demonstrated using a Ge-rich $\mathrm{Si}_{1-\mathrm{x}} \mathrm{Ge}_{\mathrm{x}}$ approach. Spiral waveguides, adiabatic tapers, multimode interference couplers and Mach-Zehnder interferometers have been designed, fabricated and characterized, showing broadband robust operation over the entire available wavelength range from $\lambda \approx$ $5.1 \mu \mathrm{m}$ to $\lambda \approx 8.6 \mu \mathrm{m}$. These results provide a solid basis to develop a competitive mid-IR integrated platform which could potentially exploit the complete Ge transparency window, up to $\lambda \approx 15 \mu \mathrm{m}$.

ACKNOWLEDEMENTS- This project has received funding from the European Research Council (ERC) under the European Union's Horizon 2020 research and innovation program (grant agreement $\left.\mathrm{N}^{\circ} 639107-\mathrm{INsPIRE}\right)$.

\section{REFERENCES}

[1] R. Soref, "Mid-infrared photonics in silicon and germanium," Nat. Photonics, 4(8), 495-497 (2010).

[2] Editorial "Extending opportunities," Nat. Photonics, 6(7) 407-407 (2012)..

[3] A. Malik, et al., "Germanium-on-silicon mid-infrared arrayed waveguide grating multiplexers," IEEE Photonics Technology Letters, 25(18), 1805-1808 (2013).

[4] G. Z. Mashanovich et al., "Germanium Mid-Infrared Photonic Devices," in J. Lightwav. Technol. 35(4) pp. 624-630 (2017).

[5] L. Carletti, et al., "Nonlinear optical response of low loss silicon germanium waveguides in the midinfrared," Optics express, 23(7), 8261-8271 (2015).

[6] J. M. Ramirez, et al., "Ge-rich graded-index Si1-xGex waveguides with broadband tight mode confinement and flat anomalous dispersion for nonlinear mid infrared photonics," Opt. Express 25, 6561-6567 (2017).

[7] J. M. Ramirez, et al., "Low-loss Ge-rich Si0.2Ge0.8 waveguides for mid-infrared photonics," Optics Letters, 42(1), 105-108 (2017). 